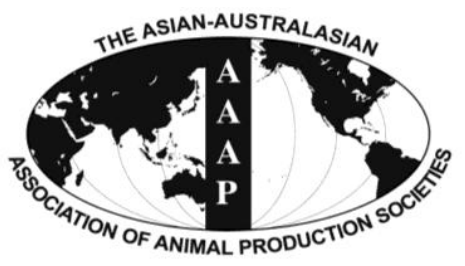

Asian Australas. J. Anim. Sci.

Vol. 26, No. 9 : 1329-1338 September 2013

http://dx.doi.org/10.5713/ajas.2013.13124

www.ajas.info

pISSN 1011-2367 elSSN 1976-5517

\title{
The Relationship between Farmers' Perceptions and Animal Welfare Standards in Sheep Farms
}

\author{
I. Kılıç* and Z. Bozkurt ${ }^{1}$ \\ Department of Biostatistics, Faculty of Veterinary Medicine, Afyon Kocatepe University, \\ TR-03200-Afyonkarahisar, Turkey
}

\begin{abstract}
In this study, we investigated the relationship between welfare standards in sheep farms and farmers' perceptions of factors affecting animal welfare. We developed a scale of 34 items to measure farmers' perceptions of animal welfare. We examined the relationships among variables in farmers' characteristics, our observations, and farmers' expressed perceptions through a t test, variance analysis and correlation analysis. Results of the research suggested that higher welfare standards for sheep exist on farms run by farmers who have a higher perception level of animal welfare. These farmers believed that personnel and shelter conditions were more effective than veterinary inspection, feeding and other factors in terms of animal welfare. In addition, we detected a significant relationship between the farmers' perceptions and their gender, educational level, whether they enjoyed their work, or whether they applied the custom of religious sacrifice. Our results showed that emotional and cognitive factors related to farmers' perceptions may offer opportunities for progress in the domain of animal welfare. (Key Words: Animal Welfare, Farmer' Perception, Perceptions-welfare Relationship, Sheep)
\end{abstract}

\section{INTRODUCTION}

In recent years, consumer interest in the relationships among food quality, food safety and welfare of farm animals has grown, and this trend has given animal welfare concerns a more prominent position on political agendas (Fraser, 2001; Hemsworth, 2007). Humans use animals for diverse purposes, such as fabric and food production, assisting disabled people, protection, flock management, research, religious ceremonies, sports, entertainment and social support. Through these varied uses of animals, different relationships have been established between humans and animals and various types of interactions have been formed (Bokkers, 2006).

Researchers detected significant effects of humananimal interactions on the behaviour, physiology, yield and welfare of farm animals for pigs (Hemsworth and Barnett, 1991; Coleman et al., 2000; Kauppinen et al., 2012), dairy

\footnotetext{
* Corresponding Author: İ. K1lıç. Tel: +90-272-228-1312, Fax: +90-272-228-1349, E-mail: kilicibrahim@hotmail.com

1 Department of Animal Husbandry, Faculty of Veterinary Medicine, Afyon Kocatepe University, TR-03200-Afyonkarahisar, Turkey.

Submitted Feb. 25, 2013; Accepted May 6, 2013; Revised May 26, 2013
}

cattle (Hemsworth et al., 1998; Breuer et al., 2003; Windschnurer et al., 2008), sheep (Hemstworth et al., 2000; Phillips and Phillips, 2010) bulls (Mounier et al., 2006) and veal-calves (Lensink et al., 2001).

Kielland et al. (2010) reported that perception and attitude of farmers directly relate to human-animal interactions and these attitudes and perceptions affect farmers' behaviour towards animals and animal welfare. This issue has been addressed in many studies (Hemsworth and Coleman, 1998; Coleman et al., 2000; Hemsworth et al., 2000; Hemsworth, 2004).

Modern livestock-raising systems with a high density of animals have affected the attitudes of farmers towards animals (Hemsworth et al., 1998). Just a few decades ago, animal production only aimed to meet the needs of society at the lowest cost. While traditionally a good farmer was viewed as a person who was proud of his or her job and skilled at the technical demands of the profession, current societal expectations of farmers include more complex requirements, such as their limitation of production, ability to increase the product's quality and respect for animal welfare and global professional ethics (Fraser, 2001; Dockes and Kling-Eveillard, 2006).

The quality of stockmanship has a major influence on 
farm animal welfare and productivity. Farmers' attitudes are reflected in their behaviour towards animals which, in turn, affects animal behaviour, welfare and productivity (Hemsworth and Coleman, 1998; Hemsworth et al., 2002; Bokkers, 2006). Kauppinen et al. (2012) reported that piglet productivity was significantly related with farmers' attitudes and attitude-related perceptions.

Perception is closely related to opinions, attitudes and behaviours. Te Velde et al. (2002) asserted that the farmers' perceptions seem to be based on a collective tradition with shared convictions, values, norms, and interests and on knowledge that is derived from comparable rearing, schooling and daily experiences on the farm. Furthermore, it has been reported that farmers' perceptions of animal welfare are affected by professional background, experience, society and the market, while farmers' attention to animal welfare is related with different factors such as additional cost, decline in competition, high standards for welfare, education and knowledge (Coleman et al., 2003; Dockes and Kling-Eveillard, 2006; Kauppinen et al., 2012).

Cognitive-behavioural modification techniques are based on the idea that people have a schema for a particular set of objects which can be used to retrain farmers' behaviour, as well as change their attitudes and beliefs (Hemsworth and Coleman, 1998; Bokkers, 2006). Hemsworth et al. (2002) argued that cognitive-behavioural interventions that successfully target the key attitudes and behaviour of stockpeople and regulate the cow's fear of humans seem to offer the industry promising methods to improve the productivity of cows.

Based on the framework provided above, we conducted this study on sheep farms to answer the following question: Do farmers' (employers') animal welfare perceptions have effects on the conditions that they supply for their animals? Specifically, this study aimed to examine the relationship between farmers' perceptions concerning factors affecting animal welfare and quantitative and qualitative observations related to some measurements and criteria that were performed to determine animal welfare levels (standards) on sheep farms.

\section{MATERIALS AND METHODS}

\section{Collection of data}

This research was performed on 100 sheep farms operating in 19 villages of the Şuhut, Emirdağ, Çay and Sultandağ1 districts of Afyonkarahisar province, which has the largest share of red meat production in Turkey in addition to being vital to livestock breeding. A stratified sampling method, which is one type of probability sampling methods, was used to select sheep farms.

The sample size was calculated with the formula ( $\left.n=\sigma^{2} Z_{\alpha}^{2} / d^{2}\right)$ proposed for large populations and survey researches (Sekaran, 2003). As a result of the pilot application on 30 people, standard deviation $\sigma=0.75$, effect size $\mathrm{d}=0.15$ and $\mathrm{Z}_{0.05}=1.96$ (for significance level $\alpha=$ 0.05 ) were used as parameters in the formula and minimum sample size was calculated as 97 farmers through the formula.

An observation form including qualitative and quantitative variables was created for the collection and evaluation of data on the factors affecting animal welfare, such as housing, care and administration and some technical breeding applications on sheep farms. This observation form included a total of 85 variables consisting of measurements and criteria that were performed to determine animal welfare levels on sheep farms. The qualitative and quantitative observations were obtained by visiting the farms. A meter, thermometer and hygrometer were used for measurements related to shelter size, capacity and conditions. Gas measurements were taken by researchers inside the housings in the mornings at 05.30 to $6.30 \mathrm{~h}$ with a digital BW GasAlertMicro 5 IR brand gas measurement device. The data related to other parameters in the form were collected through face to face interviews with the farmers and a study of their records. After a study of the farmers' declarations and their records, various data have been categorized. If the health of animals is checked at least twice per month the animals are considered to have regular health checks. In order to determine the presence of clinical mastitis farmers were asked the question "have more than 5\% (Philpot and Hickerson, 2000; Bergonier et al., 2003) of the animals in your herds been diagnosed with mastitis during the past year and the farms of farmers who replied affirmatively to this question were considered to "have mastitis" while the farms of those who replied negatively were considered "not to have mastitis". It was determined whether or not farms used dipping (sheep bath) facilities for the control of ectoparasites. The farmers who answered positively to the question about keeping the pens clean and dry and sprinkling caustic lime dust often were assessed as taking precautions to avoid foot diseases in sheep while those who replied in the negative were considered as not taking such precautions. Common diseases in herds and their treatments methods were determined. It was determined whether routine vaccinations, vitamin and mineral supplement applications were provided to protect the health of herds. Observations collected under 13 dimensions are displayed below.

Shelter size and capacity (8): volume and area per sheep, window area, door width, chimney area, capacity (for sheep, lamb, ram)

Shelter conditions (9): temperature, humidity, carbon dioxide, oxygen, ammonia, shelter age, division status in the shelters, lighting, building materials

Personnel status (6): personnel number, personnel 
educational levels, personnel experience, social security status of personnel, training status of the personnel on animal health and breeding, training level of the personnel in animal welfare

Health status (9): performing regular health control of animals, observed diseases, precautions against foot diseases, presence of clinic mastitis, availability of dipping facilities, treatments methods of diseases, vaccinations applications, vitamin applications, mineral applications

Feeding conditions (4): usage of concentrate feed, usage of roughage feed, usage of licking blocks, flushing procedure

Herd yield (9): pregnancy ratio, birth ratio, fertility ratio, lamb yield, aborting ratio, multiple birth rate, difficult birth ratio, number of sheep undergoing extractions, the reasons for the extraction

Pasture conditions (7): pasture size, surface structure of pastures, porch status in the pasture, pasture and water source distance, check-out time for pasture, pasture rotation time, the general flora of pastures

Measurements (3): live weight measurements, milk measurements, wool measurements

Milk and milking status (5): consumption or marketing of milk; age, number, education, and experience of personnel for milking

Shearing and wool status (8): shearing time, the frequency of shearing, shearing method, type of shears, number/education/experience of personnel for shearing, usage of wool

Lamb feeding status (10): mean feeding time, mean number of lambs for feeding, feeding program, weighingshearing of lambs, evaluation style of feeding lambs, diseases of feeding lambs, ear-tail-horn-cutting situation

Cleaning and manure status (3): cleaning method of shelters, cleaning frequency of shelters, manure evaluation

Other (4): sheep were named, the mean number of dogs per farm, dog breeds, gender of dogs

In the study, a scale consisting of 34 items belonging to 5 dimensions (shelter, feeding, personnel, veterinary inspection and animal emotion, other) was developed to determine perceptions of farmers who are employers of these farms on factors affecting animal welfare (Table 1). Each item in the scale was subjected to the Likert (1967) style of grading; and farmers' perceptions of the level of impact of each item on animal welfare was scored as "not effective $=1$ ", "less effective $=2$ ", "intermediately effective $=3$ ", "very effective $=4$ " and "fully effective $=5$ ". Additionally, along with the scale developed, some variables such as gender, age, educational level, time of involvement with livestock breeding, level of enthusiasm in job performance, desire to continue to do this job and practice of religious sacrifice were included to determine the personal characteristics of farmers in the survey.
We benefited from literature related to animal welfare and expert opinions in the process of developing both the observation form and the perception scale in the study. In addition, pilot application was performed for parameter estimation and rewriting the unclear items. Davis (1992) technique was utilized in the evaluation of the expert views concerning the scale. The Davis technique measures expert views (rated out of four) as (a) appropriate, (b) item should be revised slightly, (c) item should be revised strongly, (d) item is not appropriate. The final version of the perception scale was generated by performing the validity and reliability studies applied on a total of 100 farmers (one farmer per farm) within the framework of expert views and pilot application. Farmers forming the sample were owners of their farms as well as the ones in their households (husband-wife, father-mother-child) who had the most responsibility for the farm. A total number of 100 participants contributed to our research, $12 \%$ were female while $88 \%$ were male. The age ranges of the participants were 18 to $30(20 \%), 31$ to $40(25 \%), 41$ to $50(35 \%)$ and 51 to $80(20 \%)$ years of age.

\section{Statistical analysis}

In our research, perceptions of farmers on factors affecting animal welfare were described by calculating mean and standard deviation for each dimension. The differences between farmers perceptions which were determined by the mean of 34 items in the scale according to their personal characteristics were tested by independent samples $t$ and variance analysis (ANOVA). We utilized the Tukey test to make a dual comparison of groups. Additionally, we applied exploratory factor analysis to the scale used in the research. In the factor analysis, principal component analysis for extraction method and varimax with Kaiser normalization for rotation method were performed. Furthermore, we calculated Cronbach's Alpha coefficients for reliability analysis of the scale.

Relationship between quantitative observations done to determine animal welfare standards and general farmers' perceptions related with factors affecting animal welfare was determined with Pearson's correlation analysis (Table 3). Relationship between qualitative observations and farmers' perceptions was determined with independent samples $t$ test (Table 4). We included findings in which relations between 85 variables of observations and farmers' perceptions reflected a significant correlation. The level of the relationship between variables was defined as "very poor" when Pearson's correlation coefficient was below 0.19 ; "poor" for 0.20 to 0.39 ; "medium" for 0.40 to 0.59 ; "strong" for 0.60 to 0.79 and "very strong" for 0.80 to 1.00 .

Total scale scores were taken into consideration instead of sub-scale scores in the relation between variables for two reasons: firstly our study tested whether a relationship 
Table 1. Item, subscale and total scale statistics for the animal welfare perception scale

\begin{tabular}{|c|c|c|c|c|c|c|}
\hline Subscales and items & $\begin{array}{c}\text { Factor } \\
\text { loadings }\end{array}$ & $\begin{array}{l}\text { Item-scale } \\
\text { correlation }\end{array}$ & Eigenvalues & $\begin{array}{c}\% \text { of } \\
\text { variance }\end{array}$ & $\begin{array}{l}\text { Cronbach's } \\
\text { Alpha }\end{array}$ & $\begin{array}{l}\text { Mean } \\
( \pm \text { SD })\end{array}$ \\
\hline \multicolumn{7}{|l|}{ Shelter conditions } \\
\hline Size and capacity of shelter (area per sheep) & 0.70 & 0.52 & 10.33 & 32.88 & 0.83 & 3.74 \\
\hline Cleaning of shelter & 0.63 & 0.55 & & & & $( \pm 0.77)$ \\
\hline Ventilation status or system indoor & 0.64 & 0.54 & & & & \\
\hline Temperature in shelter & 0.63 & 0.55 & & & & \\
\hline Moisture in shelter & 0.66 & 0.59 & & & & \\
\hline Gases in shelter & 0.74 & 0.49 & & & & \\
\hline Lighting in shelter & 0.56 & 0.47 & & & & \\
\hline Shelter insulation & 0.74 & 0.48 & & & & \\
\hline Noise in shelter & 0.57 & 0.48 & & & & \\
\hline Ground or floor surface conditions in shelter & 0.70 & 0.59 & & & & \\
\hline \multicolumn{7}{|l|}{ Feeding conditions } \\
\hline Quality of feed & 0.68 & 0.53 & 6.32 & 20.14 & 0.80 & 3.58 \\
\hline Quality of water & 0.73 & 0.58 & & & & $( \pm 0.80)$ \\
\hline Feeding equipments characteristics & 0.59 & 0.41 & & & & \\
\hline The size of the outside feeding area & 0.72 & 0.57 & & & & \\
\hline Flora of the outside feeding area & 0.61 & 0.49 & & & & \\
\hline \multicolumn{7}{|l|}{ Personnel conditions } \\
\hline Behaviour towards animals & 0.58 & 0.39 & 5.21 & 16.60 & 0.80 & 3.88 \\
\hline Mean education level & 0.42 & 0.55 & & & & $( \pm 0.74)$ \\
\hline Knowledge of animal welfare & 0.40 & 0.43 & & & & \\
\hline Experience in sheep farming & 0.72 & 0.51 & & & & \\
\hline $\begin{array}{l}\text { Motivation (housing-working conditions, } \\
\text { wage, social security, etc.) }\end{array}$ & 0.69 & 0.48 & & & & \\
\hline Overall happiness in performing her/his job & 0.56 & 0.7 & & & & \\
\hline \multicolumn{7}{|l|}{ Veterinary inspection and animal emotion } \\
\hline Regular health check carried out by a veterinarian & 0.51 & 0.43 & 2.24 & 7.14 & 0.88 & 3.65 \\
\hline Type and methods of the treatment & 0.42 & 0.35 & & & & $( \pm 0.72)$ \\
\hline $\begin{array}{l}\text { Minerals and vitamins given to animals } \\
\text { under veterinary control }\end{array}$ & 0.62 & 0.42 & & & & \\
\hline Pain or suffering of animals & 0.55 & 0.46 & & & & \\
\hline Wellbeing of animals & 0.41 & 0.34 & & & & \\
\hline Fatigue of animals & 0.46 & 0.38 & & & & \\
\hline \multicolumn{7}{|l|}{ Other conditions } \\
\hline Conditions that can cause nervousness & 0.47 & 0.40 & 1.79 & 5.70 & 0.75 & 3.51 \\
\hline Conditions affecting reproductive process & 0.44 & 0.37 & & & & $( \pm 0.67)$ \\
\hline The relationship between sheep and their lambs & 0.46 & 0.40 & & & & \\
\hline $\begin{array}{l}\text { Technical equipments used for milking, } \\
\text { shearing and mutilations }\end{array}$ & 0.46 & 0.38 & & & & \\
\hline Feeling of safety of animals & 0.43 & 0.36 & & & & \\
\hline Acceptance of an animal as individual & 0.43 & 0.46 & & & & \\
\hline Giving names to animals & 0.45 & 0.31 & & & & \\
\hline General or total scales & & & & 82.46 & 0.91 & $\begin{array}{r}3.68 \\
( \pm 0.77)\end{array}$ \\
\hline
\end{tabular}

Kaiser-Meyer-Olkin measure of sampling adequacy: $\mathrm{KMO}=0.824$; Bartlett's test of sphericity: $x^{2}=2,421.3 ; \mathrm{p}=0.001$.

existed between farmers' general perceptions and our observations of animal welfare conditions on sheep farms, secondly item-scale correlation coefficients were found to be over 0.30. Furthermore, we found more significant relationships in the analysis of total scores than in the analysis of sub-scale scores. SPSS for Windows and Microsoft Excel programs were utilized in analysis of data obtained in the research.

\section{RESULTS}

The factor loadings, item-scale correlation, eigenvalues, percentage of variance explanation, cumulative variances, reliability (Cronbach's Alpha) coefficients, means and 
Table 2. The relationship between personal characteristics of farmers and their animal welfare perceptions

\begin{tabular}{lccccc}
\hline Variables & Groups & $\mathrm{n}$ & Means & SD & $\mathrm{p}$ \\
\hline Gender & Female & 12 & 4.27 & 0.73 & $0.009^{*}$ \\
Education level & Male & 88 & 3.61 & 0.75 & \\
& College and university & 11 & $4.22^{\mathrm{a}}$ & 0.83 & $0.035^{*}$ \\
& Secondary school & 18 & $3.70^{\mathrm{b}}$ & 0.61 & \\
Enjoyment in performing her/his job & Elementary school & 71 & $3.59^{\mathrm{b}}$ & 0.78 & \\
& Always & 46 & $4.00^{\mathrm{a}}$ & 0.67 & $0.000^{*}$ \\
Religious sacrificing status & Generally & 40 & $3.49^{\mathrm{b}}$ & 0.58 & \\
& Never or rarely & 14 & $3.20^{\mathrm{c}}$ & 0.62 & \\
& Yes & 87 & 3.58 & 0.73 & $0.000^{*}$ \\
\hline
\end{tabular}

$* \mathrm{p}<0.05{ }^{\mathrm{a}, \mathrm{b}, \mathrm{c}}$ Means of groups followed by different letters differ significantly at $\mathrm{p}<0.05$.

standard deviations of each dimension (sub-scales) related with animal welfare perception scale applied in the research are given in Table 1. As a result of exploratory factor analysis applied for the scale consisting of 34 items, we determined that a scale accumulated under 5 factors which had an eigenvalue greater than 1 and described $82.46 \%$ of the total variance. The "shelter conditions" factor, which has the greatest share and includes 10 items, described $32.88 \%$ of the total variance. In addition to this, we detected that findings were over critical values; factor loadings for each item in the scale were above 0.4 while item-scale correlation coefficients were above 0.3 . Barlett's test $\left(x^{2}=\right.$ 2,421.3; $\mathrm{p}<0.001)$ allowed us to detect applicability of factor analysis. The Kaiser-Meyer-Olkin value (KMO = 0.824 ) calculated showed that the sample size was sufficient. On the other hand, we determined that Cronbach's Alpha coefficients which were calculated for reliability analysis of factors in the scale had changed between 0.75 and 0.88 ; and this value was 0.91 for the general scale.

The mean $(\bar{X}=3.679)$, which was calculated for the general scale of 34 items in Table 1, indicated that farmers' perceptions were above the intermediate level in other words they were not too high. When we examined the mean calculated for each dimension (factor) in the scale, we saw that farmers held the perception that issues related with personnel were the most effective $(\bar{X}=3.88)$. This was followed by shelter $(\bar{X}=3.74)$, veterinary inspection and animal emotion $(\bar{X}=3.65)$, feeding $(\bar{X}=3.58)$ and other $(\bar{X}=3.51)$ factors.

The results of independent samples $t$ test and variance analysis (ANOVA) for comparison according to individual characteristics of animal welfare perception of farmers that formed the sample group of the research are given in Table 2. Significant relationships were detected between farmers' perception and gender, educational level, level of enthusiasm in job performance and religious sacrifice status $(\mathrm{p}<0.05)$. It was determined that the relationship between farmers' perceptions and age, the period dealing with stock breeding and desire to continue doing this job were not statistically significant $(\mathrm{p}>0.05)$.

Means of groups showed that women $(\bar{X}=4.27)$ have the perception that issues (items) specified in the scale have a greater impact on animal welfare than men $\operatorname{did}(\overline{\mathrm{X}}=$ 3.61). On the other hand, the scale showed that farmers who graduated from high school and university have the highest mean $(\bar{X}=4.22)$. This finding suggests that, by increasing the educational level of farmers, perception of animal welfare may increase. Furthermore, we detected that farmers who "always" enjoy their work and do not practice religious sacrifice have a higher perception of animal welfare than other groups (Table 2).

The correlation coefficients (r) presented in Table 3 indicated significant relationships between observations performed to determine animal welfare in sheep farms and farmers' expressed perceptions, and the results of independent samples $\mathrm{t}$ test were presented in Table 4.

Table 3. The relationship between farmers' perceptions and quantitative observations

\begin{tabular}{lcc}
\hline Variables & Means & $\begin{array}{c}\text { Correlation } \\
\text { coefficients }(\mathrm{r})\end{array}$ \\
\hline Capacity per farm & 197.13 & $-0.346^{*}$ \\
Volume per sheep $\left(\mathrm{m}^{3}\right)$ & 2.23 & $0.436^{*}$ \\
Area per sheep $\left(\mathrm{m}^{2}\right)$ & 0.75 & $0.421^{*}$ \\
Window area $\left(\mathrm{m}^{2}\right)$ & 2.31 & $0.223^{*}$ \\
Door width $(\mathrm{m})$ & 1.39 & $0.208^{*}$ \\
Chimney area $\left(\mathrm{m}^{2}\right)$ & 0.82 & $0.211^{*}$ \\
Temperature $\left({ }^{\circ} \mathrm{C}\right)$ & 21.05 & $-0.148^{*}$ \\
Humidity $(\%)$ & 43.20 & $-0.186^{*}$ \\
Carbon dioxide (ppm) & $1,556.36$ & $-0.409^{*}$ \\
Oxygen (ppm) & 20.43 & $0.376^{*}$ \\
Ammonia (ppm) & 58.02 & $-0.421^{*}$ \\
Personnel number & 4.56 & $-0.154^{*}$ \\
Personnel education level $(\mathrm{yr})$ & 6.13 & $0.409^{*}$ \\
Personnel experience $(\mathrm{yr})$ & 21.14 & $0.235^{*}$ \\
Birth rate $(\%)$ & 79.20 & $0.166^{*}$ \\
Aborting ratio $(\%)$ & 7.33 & $-0.151^{*}$ \\
\hline
\end{tabular}


Table 4. The relationship between farmers' perceptions and qualitative observations

\begin{tabular}{|c|c|c|c|c|c|c|}
\hline Variables & Groups & $\mathrm{n}$ & $\begin{array}{l}\text { Perception } \\
\text { means }(1-5)\end{array}$ & SD & $\mathrm{t}$ & $\mathrm{p}$ \\
\hline \multirow[t]{2}{*}{ Social security status of personnel } & No & 23 & 3.33 & 0.75 & 2.533 & $0.016^{*}$ \\
\hline & Yes & 77 & 3.78 & 0.74 & & \\
\hline \multirow{2}{*}{$\begin{array}{l}\text { Training status of the personnel } \\
\text { on animal health and breeding }\end{array}$} & No & 92 & 3.61 & 0.73 & 2.988 & $0.004 *$ \\
\hline & Yes & 8 & 4.42 & 0.75 & & \\
\hline \multirow[t]{2}{*}{ Division status at the shelters } & No & 74 & 3.57 & 0.68 & 2.298 & $0.024 *$ \\
\hline & Yes & 26 & 3.97 & 0.93 & & \\
\hline \multirow[t]{2}{*}{ Use of concentrate feed } & Home & 40 & 3.86 & 0.84 & 2.014 & $0.047 *$ \\
\hline & Factory & 60 & 3.55 & 0.70 & & \\
\hline \multirow[t]{2}{*}{ Use of licking blocks } & No & 30 & 3.42 & 0.88 & 2.218 & $0.029 *$ \\
\hline & Yes & 70 & 3.78 & 0.69 & & \\
\hline \multirow[t]{2}{*}{ Flushing procedure } & No & 95 & 3.63 & 0.74 & 2.444 & $0.016^{*}$ \\
\hline & Yes & 5 & 4.40 & 0.83 & & \\
\hline \multirow[t]{2}{*}{ Performing live weight measurements } & No & 25 & 3.89 & 0.53 & 2.051 & $0.044 *$ \\
\hline & Yes & 75 & 3.60 & 0.82 & & \\
\hline \multirow[t]{2}{*}{ Performing milk measurements } & No & 60 & 3.80 & 0.89 & 2.061 & $0.041 *$ \\
\hline & Yes & 40 & 3.51 & 0.51 & & \\
\hline \multirow[t]{2}{*}{ Performing wool measurements } & No & 50 & 3.83 & 0.77 & 2.108 & $0.037 *$ \\
\hline & Yes & 50 & 3.52 & 0.73 & & \\
\hline \multirow[t]{2}{*}{ Consuming or marketing of milk } & Home & 45 & 3.85 & 0.80 & 2.099 & $0.038 *$ \\
\hline & Marketing & 55 & 3.53 & 0.71 & & \\
\hline \multirow[t]{2}{*}{ Usage of wool } & Home & 35 & 3.89 & 0.84 & 2.054 & $0.043 *$ \\
\hline & Marketing & 65 & 3.57 & 0.70 & & \\
\hline \multirow[t]{2}{*}{ Performing regular animal health controls } & No & 20 & 3.30 & 0.71 & 2.570 & $0.012 *$ \\
\hline & Yes & 80 & 3.77 & 0.75 & & \\
\hline \multirow[t]{2}{*}{ Clinic mastitis } & No & 15 & 4.11 & 0.71 & 2.431 & $0.017 *$ \\
\hline & Yes & 85 & 3.60 & 0.75 & & \\
\hline \multirow[t]{2}{*}{ Sheep were named } & No & 65 & 3.47 & 0.67 & 3.784 & $0.000 *$ \\
\hline & Yes & 35 & 4.05 & 0.80 & & \\
\hline
\end{tabular}

$* \mathrm{p}<0.05$

According to these findings, "very poor" relationships were detected between farmers' perceptions and temperature, humidity, number of personnel, birth and aborting ratio; "poor" relationships were detected between farmers' perceptions and capacity, window area, door width, chimney area, oxygen and personnel experience; "intermediate" relationships were detected between farmers' perception and volume per sheep, area per sheep, carbon dioxide, ammonia and personnel education period. A negative correlation was found between capacity, temperature, humidity, carbon dioxide, ammonia, number of personnel, aborting ratio and farmers' perceptions regarding animal welfare; and a positive correlation was found for other variables.

According to $\mathrm{t}$ test results in Table 4; perceptions of farmers (employers) who provide health insurance for their personnel, whose personnel had been trained in animal health, who create sections in their shelters, make their concentrate feed by themselves, keep licking blocks, provide flushing procedure, have farms where live weight, milk, and wool measurements are not performed, use milk and produce wool at home, perform health controls, had sheep who showed no signs of clinic mastitis and those who named their sheep had a higher (positive) perception in terms of animal welfare than the farmers in other groups.

\section{DISCUSSION}

It was detected in the research that animal welfare perception scale consisting of 34 items was accumulated under five factors and showed a high reliability level of the calculated Cronbach's Alpha values. The mean calculated for the general scale indicated that the Muslim farmers have an intermediate perception of factors affecting animal welfare. Most of the farmers who replied to the questionnaire believe that sheep are "sentient creatures" and name their sheep, which also suggests that they have positive perceptions of animal welfare.

Our research showed that personnel and shelter conditions were more effective than feeding, veterinary 
inspection and animal emotion and other conditions according to farmers' welfare perception. It is considered that differences between farmers' perceptions may be the reason for differences between the main beliefs and morals of farmers, which form the basis to their welfare perception (Coleman and Hemsworth, 1998). The research/scale revealed that animal welfare perception of farmers is based on emotions, biological functionality and natural life conditions or an attitude including all three concepts (Fraser et al., 1997; Vanhonacker et al., 2008). The farmers in the study believed that attitudes and behaviours of personnel most affected the level of animal welfare. Boivin et al. (2007) reported that they believe that animal management will improve by virtue of positive human treatment in addition to facility quality.

We determined through this research that some demographic characteristics are correlated with welfare perception. Female farmers have a stronger perception that certain issues (items) specified in the scale have a greater impact on animal welfare than male farmers. Similar findings were also emphasized in studies conducted by Herzog (2007), Furnham and Pinder (1990) and Heleski et al. (2004). A possible reason that female farmers place stronger emphasis on animal welfare than male farmers may be related to the many emotional and cognitive hypothesizes: females have more animal-centered thoughts than men (Maria, 2006), men are encouraged to be less emotional and more utilitarian while women are encouraged to care for and feed others, men view animals only as a means to survive (e.g. food supply) (Herzog et al., 1991), men and women have different moral orientations affecting their perspectives of their animals (Kellert and Berry, 1987), women are more sensitive to the ethical treatment of animals than men are, women are more liberal and men are more conservative or men are more attracted to traditional practices such as using animals for survival (Furnham and Pinder, 1990; Pifer et al., 1994; Knight et al., 2004).

Most of the 100 farmers ( 87 farmers) who replied to the questionnaire reported that they practice religious sacrifice, while only 13 have reported that they do not. Most of the farmers ( 9 farmers) who reported that they do not sacrifice were women. The main reason for not sacrificing reported by both male and female farmers was economical (family budget cannot afford a second sacrificial animal if the husband/wife/father sacrifices an animal in patriarchal families). However, other researchers have suggested that the less conservative attitudes of women towards traditional practices, including animal usage, (Furnham and Pinder, 1990; Pifer et al., 1994; Knight et al., 2004) and/or emotional and cognitive factors, such as women expressing more positive attitudes towards animals than men may affect this result as reported by Signal and Taylor (2006) and Coleman (2008).
We determined that the educational level and farmers enjoying the job had effects on welfare perception. We expected to find these results. Kellert (1988) noted a positive relationship between farmers' educational level and attitude towards animals. Kellert's research also revealed that farmers with a high animal welfare perception provided training to their personnel about animal health and welfare. These findings also gave support for cognitive-behavioural training aimed at fermenting attitudes and behaviours among personnel who are responsible for animal care and management and have direct contact with animals may be used to increase the level of animal welfare and yield (Carless et al., 2007).

Farmers who reported a high level of job satisfaction (and/or always carry out their business fondly) have a greater welfare perception level (Hemsworth and Coleman, 2010). Hence, most of the farmers who replied to the questionnaire reported that they enjoyed raising sheep and did not wish to change their profession. This result indicates that farmers are in their businesses voluntarily and therefore have high levels of job satisfaction and motivation. Most of the farmers involved in the survey also have worked in the care and management of animals.

In the research, no significant relation was detected between farmers' welfare perception and age. Similarly, Köhler (2001) reported that consumers' animal welfare perception is not affected by age. Maria (2006) reported that the interest in animal welfare is expressed more often by young and middle-aged persons and less often by elders. In this study, the lack of difference in opinion among farmers in terms of age may be attributed to the fact that the farmers in this study have been in this business, and surrounded by sheep, since childhood.

The research did reveal a difference in perception for animal welfare related to the difference in size of farms among the surveyed farmers. When farm capacity increases farmers' perceptions of animal welfare were negative or less than farmers with smaller farms. Hence, we found a negative relationship between the number of personnel, which increases related with farm size, and welfare perception. Based on these results which can be considered just interesting at first view, we thought that farmers on bigger farms, where sheep are raised in high density conditions, have less favorable views on the humane treatment of animals. Trends such as less time spent with individual animals because of animal density; fewer positive interactions with animals such as talking, touching and cuddling them; fewer human-animal interactions on big farms where stock is managed not by the individual but rather by use of technological innovations and the goal of the business focused more on income than with survival may cause this discrepancy (Smith and Grenfell, 1990; Fraser, 2005). In addition, Dockes and Kling-Eveillard 
(2006) reported that the farmers who were deeply interested in the technical and economic aspects of their occupation did not consider the relationship to the animals as an essential point of their job. The authors also mentioned that these farms mainly take the physiological needs of the animals (health and food) into account and assume that they are satisfying them. Hence, we detected that welfare perception is higher among farmers of small farms, where live weight and live weight increase, and milk and wool yields are not measured; milk and wool are consumed at home. Furthermore, farmers who sell milk and wool and obtain monetary gains have more negative attitudes about animal welfare.

According to our results, it is interpreted that some health indicators on the farms of farmers who expressed a high level of welfare perception is better. Farmers on these farms continuously observe their sheep's health and wellbeing. We identified a positive correlation between animal welfare perception and birth ratios on the farms of farmers in the survey and a negative correlation between perception and abort ratio. Furthermore, we found that there were no cases of clinic mastitis on the farms of farmers who represented a higher level of welfare perception than the others. These results showed that health and performance of sheep on these farms were good which was reflected on the welfare standards which were also good (Broom, 1991; Sevi et al., 1999). Furthermore, we detected that sectioning in the shelters was based on the breeding and needs of animals on these farms and this indicates that farmers monitor the sheep for health issues and observe their social interactions (Sevi et al., 2003; Caroprese, 2008).

Farmers who expressed a positive view or high level of perception of animal welfare employed trained and experienced personnel and provided social security, which is an important factor in personnel motivation and job satisfaction. When taking into consideration that there is a basic relationship between human perception and attitudes (cognitive, emotional and behavioural dimensions), it was concluded that the farmers' attitude and behaviour may have been affected by their perception. Job motivation is very important as it affects other characteristics related with the job. Job satisfaction is generally affected by awards (personal or financial), job design and enrichment, involvement in the decision-making process, job performance and working environment (Hemstworth and Coleman, 1998). Personnel working on farms should have some knowledge and the skills necessary to perform their jobs with animals. Hemsworth et al. (1981) and Coleman et al. (1998) recorded a positive correlation between negative behaviour of the personnel and tendency of female pigs to run away from humans; Waiblenger et al. (2002) reported that positive behaviour of personnel are negatively correlated with animals' tendency to run away from humans.
These findings indicate that farmers' perception, attitudes and behaviours have a significant effect on animal fear and accordingly on yield and welfare.

\section{CONCLUSION}

Significant relationships were found between farmers' animal welfare perception and welfare status of animals on their farms. The farmers believed that personnel and shelter conditions were more effective than veterinary inspection and animal emotion, feeding and other conditions for animal welfare. According to this result, if more female and university graduated farmers are encouraged to enter into sheep farming, we can expect that conventional welfare views, sheep farm standards and practices in the region will be improved in future. While the area per sheep and oxygen level in the shelter, education and experience of the personnel and birth ratio of sheep correlated positively with the relationships between farmers' perceptions and the farm capacity, carbon dioxide and ammonia levels, temperature and humidity in the shelter, personnel number and aborting ratio were negatively correlated with farmers' perceptions. Our results indicated that the perceptions related to factors affecting animal welfare differ among the sheep farmers and their perceptions seem to be related to the welfare standards of the sheep on their farms.

\section{ACKNOWLEDGEMENTS}

This study received the support of Afyon Kocatepe University Scientific Research Projects Coordination Unit with Project number 10.VF.04, Turkey.

\section{REFERENCES}

Bergonier, D., R. De Cremoux, R. Rupp, G. Lagriffoul, and X. Berthelot. 2003. Mastitis of dairy small ruminants. Vet. Res. 34:689-716.

Boivin, X., L. Marcantognini, P. Boulesteix, J. Godet, A. Brulé, and I. Veissier. 2007. Attitudes of farmers towards Limousin cattle and their handling. Anim. Welf. 16:147-151.

Bokkers, E. A. M. 2006. Effects of interactions between humans and domesticated animals. In: Farming for Health (Ed. J. Hassink, and M. Van Dijk). Frontis: Wageningen, Netherlands. pp. 31-41.

Breuer, K., P. H. Hemsworth, and C. J. Coleman. 2003. The effect of positive or negative handling on the behavioural and physiological responses of nonlactating heifers. Appl. Anim. Behav. Sci. 84:3-22.

Broom, D. M. 1991. Animal welfare: Concepts and measurement. J. Anim. Sci. 69:4167-4175.

Carless, S. A., S. Fewings-Hall, M. Hall, M. Hay, P. H. Hemsworth, and G. J. Coleman. 2007. Selecting unskilled and semi-skilled blue-collar workers: The criterion-related validity of the PDI-employment inventory. International Journal of 
Selection and Assessment 15:335-340.

Caroprese, M. 2008. Sheep housing and welfare. Small Rumin. Res. 76:21-25.

Coleman, G. J. 2008. Public perceptions of animal welfare: an international perspective. AAWS08 International Animal Welfare Conference Gold Coast, Queensland, Australia.

Coleman, G. J., P. H. Hemsworth, and M. Hay. 1998. Predicting stockperson behaviour towards pigs fromattitudinal and job related variables and empathy. Appl. Anim. Behav. Sci. 58:6378.

Coleman, G. J., P. H. Hemsworth, M. Hay, and M. Cox. 2000. Modifying stockperson attitudes and behaviour towards pigs at a large commercial farm. Appl. Anim. Behav. Sci. 66:11-20.

Coleman, G. J., M. McGregor, P. H. Hemsworth, J. Boyce, and S. Dowling. 2003. The relationship between beliefs, attitudes and observed behaviours of abattoir personnel in the pig industry. Appl. Anim. Behav. Sci. 82:189-200.

Davis, L. L. 1992. Instrument review: Getting the most from a panel of experts. Appl. Nurs. Res. 5:194-197.

Dockes, A. C., and F. Kling-Eveillard. 2006. Farmers and advisers representations of animals and animal welfare. Livest. Sci. 103:243-249.

Fraser, D. 2001. Farm animal production: changing agriculture in a changing culture. J. Appl. Anim. Welf. Sci. 4:175-190

Fraser, D., D. M. Weary, E. A. Pajor, and B. N. Milligan. 1997. A scientific conception of animal welfare that reflects ethical concerns. Anim. Welf. 6:187-205.

Fraser, D. 2005. Animal welfare and the intensification of animal production: An alternative interpretation. FAO Readings in Ethics, Food and Agriculture Organization of the United Nations, Rome, Italy.

Furnham, A., and A. Pinder. 1990. Young people's attitudes to experimentation on animals. Psychologist 10:444-448.

Heleski, C. R., A. G. Mertig, and A. J. Zanella. 2004. Assessing attitudes toward farm animal welfare: A national survey of animal science faculty members. J. Anim. Sci. 82:2806-2814.

Hemsworth, P. H. 2004. Human-livestock interaction. In: The Well-Being of Farm Animals, Challenges and Solutions (Ed. G. J. Benson, and B. E. Rollin). Blackwell Publishing: Iowa, USA. pp. 21-38.

Hemsworth, P. H. 2007. Ethical stockmanship. Aust. Vet. J. 85:194-200.

Hemsworth, P. H. and J. L. Barnett. 1991. The effects of aversively handling pigs either individually or in groups on their behaviour, growth and corticosteroids. Appl. Anim. Behav. Sci. 30:61-72.

Hemsworth, P. H., A. Brand, and P. J. Willems. 1981. The behavioural response of sows to the presence of human beings and their productivity. Livest. Prod. Sci. 8:67-74.

Hemsworth, P. H., and G. J. Coleman. 1998. Human-livestock interactions: The stockperson and the productivity of intensively farmed animals. CAB International: Wallingford, UK.

Hemsworth, P. H., and G. J. Coleman. 2010. Managing poultry: human-bird interactions and their implications. In: The Welfare of Domestic Fowl and Other Captive Birds (Ed. I. J. H. Duncan, and P. Hawkins). Springer Dordrecht: Heidelberg, Germany. pp. 219-235.

Hemsworth, P. H., G. J. Coleman, and J. L Barnett. 1998. The effects of improving human-animal interactions on the behaviour and productivity of commercial dairy cows. Proceedings of the Australian Society for the Study of Animal Behavior. 29th Annual Conference Palmerston North. New Zealand Institute of Natural Resources, Massey University, New Zealand. pp. 15-16.

Hemsworth, P. H., G. J. Coleman, J. L. Barnett, and S. Borg. 2000. Relationships between human-animal interactions and productivity of commercial dairy cows. J. Anim. Sci. 78:28212831.

Hemsworth, P. H., G. J. Coleman, J. L. Barnett, S. Borg, and S. Dowling. 2002. The effects of cognitive behavioral intervention on the attitude and behavior of stockpersons and the behavior and productivity of commercial dairy cows. J. Anim. Sci. 80:68-78.

Herzog, H. A. 2007. Gender differences in human-animal interactions: A Review. Anthrozoos 20:7-21.

Herzog, H. A., Jr. N. S. Betchart, and R. B. Pittman. 1991. Gender, sex role orientation, and attitudes toward animals. Anthrozoos 4:184-191.

Kauppinen, T., V. K. Mikko, and A. Valros. 2012. Farmer attitude toward improvement of animal welfare is correlated with piglet production parameters. Livest. Sci. 143:142-150.

Kellert, S. R. 1988. Human-animal interactions: A review of American attitudes toward wild and domestic animals in the twentieth century. In: Animals and people sharing the world (Ed. A. N. Rowan). University Press of New England: Hanover-New Hampshire, USA. pp. 137-175.

Kellert, S. R., and J. K. Berry. 1987. Attitudes, knowledge, and behaviors toward wildlife as affected by gender. Wildl. Soc. Bull. 15:363-371.

Kielland, C., E. Skjerve, O. Østerås, and A. J. Zanella. 2010. Dairy farmer attitudes and empathy toward animals are associated with animal welfare indicators. J. Dairy Sci. 93:2998-3006.

Knight, S. E., A. Vrij, J. Cherryman, and K. Nunkoosing. 2004. Attitudes towards animal use and belief in animal mind. Anthrozoos 17:43-62.

Köhler, F. 2001. Consumer concerns about animal welfare and the impact on food choice. Report on National Survey, EU FAIR CT98-3678, The University of Kiel, Germany.

Lensink, B. J., X. Fernandez, G. Cozzi, L. Florand, and I. Veissier. 2001. The influence of farmers' behavior on calves' reactions to transport and quality of veal meat. J. Anim. Sci. 79:642-52.

Likert, R. 1967. The human organization: Its Management and Value. McGrow-Hill: New York, USA.

Maria, G. A. 2006. Public perception of farm animal welfare in Spain. Livest. Sci. 103:250-256.

Mounier, L., S. Colson, M. Roux, H. Dubroeucq, A. Boissy, S. Ingrand, and I. Veissier. 2006. Links between specialization in the finishing of bulls, mixing, farmers' attitudes towards animals and the production of finishing bulls: a survey on French farms. Anim. Sci. 82:561-568.

Phillips, C. J. C. and A. P. Phillips. 2010. Attitudes of Australian sheep farmers to animal welfare. J. Int. Farm Manag. 5:1-26.

Philpot, W. N., and S. C. Hickerson. 2000. Winning the fight against mastitis. Westphalia Surge, Naperville, USA.

Pifer, L., K. Shimizu, and R. Pifer. 1994. Public attitudes toward animal research: Some international comparisons. Soc. Anim. 2:95-113. 
Sekaran, U. 2003. Research methods for business. John Wiley High Education Press: New York, USA.

Sevi, A., S. Massa, G. Annicchiarico, S. Dell'aquila, and A. Muscio. 1999. Effect of stocking density on ewes milk yield, udder health and microenvironment. J. Dairy Res. 66:489-499.

Sevi, A., L. Taibi, M. Albenzio, G. Annicchiarico, R. Marino, and M. Caroprese. 2003. Influence of ventilation regimen on microenvironment and on ewe welfare and milk yield in summer. Italian J. Anim. Sci. 2:197-212.

Signal, T. D., and N. Taylor. 2006. Attitudes to animals: Demographics within a community sample. Soc. Anim. 14: 147-157.
Smith, G., and B. T. Grenfell. 1990. Population biology of pseudorabies in swine. Am. J. Vet. Res. 51:148-155.

Te Velde, H., N. Aarts, and C. Van Woerkum. 2002. Dealing with ambivalence: farmers' and consumers' perceptions of animal welfare in livestock breeding. J. Agric. Environ. Ethics 15: 203-219.

Vanhonacker, F., W. Verbeke, E. Van Poucke, and F. A. M. Tuyttens. 2008. Do citizens and farmers interpret the concept of farm animal welfare differently? Livest. Sci. 116:126-136.

Windschnurer, I., C. Schmied, X. Boivin, and S. Waiblinger. 2008. Reliability and inter-test relationship of tests for on-farm assessment of dairy cows' relationship to humans. Appl. Anim. Behav. Sci. 114:37-53. 